\title{
Hyperfibrinogenemia: A Novel Predictor to Identify the Necrotizing Enterocolitis in Newborn Infants
}

\author{
Zhong Liang Chen ${ }^{1,2}$, Zipu Hong ${ }^{2 \#, ~ Z u r e n ~} \mathrm{Cai}^{2}$, Xiao yang Wan ${ }^{3}$, Xiaoming Chen ${ }^{2 *}$ and Xulai Shi ${ }^{4}$ \\ ${ }^{1}$ Wuxi Children's Hospital, China \\ ${ }^{2}$ The First Affiliated Hospital of Wenzhou Medical University, China
}

${ }^{3}$ Institute of Infectious Liver Disease, Tongji Hospital of Tongji Medical College

${ }^{4}$ The Second Affiliated Hospital of Wenzhou Medical University, China

\#These authors ZLC, ZPH contributed equally to this study

*Corresponding author: Xiaoming Chen, Department of Pediatric Surgery, The First Affiliated Hospital of Wenzhou Medical

University, China

\begin{abstract}
ARTICLE INFO
Received: 彗 March 21, 2019

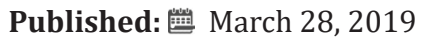

Citation: Zhong Liang C, Zipu H, Zuren $\mathrm{C}$, Xiao yang $\mathrm{W}$, Xiaoming $\mathrm{C}$, et al., Hyperfibrinogenemia: A Novel Predictor to Identify the Necrotizing Enterocolitis in Newborn Infants. Biomed J Sci \& Tech Res 16(3)-2019. BJSTR. MS.ID.002866.
\end{abstract}

Keywords: Pediatric Surgery; Diagnosis; Necrotizing Enterocolitis (NEC); Hyperfibrinogenemia
ABSTRACT

Necrotizing enterocolitis (NEC) is one of the mostcommon devastatinggastrointestinal emergencies and affect premature intestine infants. However, there is still a lack of indications for timely surgery, which cause complications and miss the optimal surgical timing. We collected plasma fibrinogen from 168 postoperative NEC patients using the pt-der method and the patients were divided into four groups, including 68 Infant patients with intestinal perforation and necrosis (IPN), 61 Infant patients of intestinal necrosis without perforation (INWP), 15 Infant patients of intestinal perforation without necrosis (IPWN), and 24 infants without necrosis and perforation (WNP). Compared to no intestinal necrosis patients, there was a significant increase of the fibrinogen level in NEC children with intestinal necrosis. This study may provide important information for early diagnosis of infant patients with intestinal necrosis for immediate decision of surgery.

Abbreviations: IN: Intestinal Necrosis; INWP: Intestinal Necrosis Without Perforation; IP: Intestinal Perforation; IPN: Intestinal Perforation and Necrosis; IPWN: Intestinal Perforation Without Necrosis; NEC: Necrotising Enterocolitis; NIN: No Intestinal Necrosis; NIP: No Intestinal Perforation; VLBW: Very Low Birth Weight; WNP: Without Necrosis and Perforation

\section{Introduction}

NEC is a common intestinal inflammatory disease, which induces high morbidity and mortality, of neonates, especially in the premature newborns and very low birth weight (VLBW) infants $(<1500 \mathrm{~g})[1,2]$. The mortality rate is particularly higher in the children requiring surgical intervention [3]. In clinical treatment, radiological and laboratory tests were applied for the initial diagnosis of NEC. When NEC is diagnosed, the patient should be treated with gastrointestinal rest, gastrointestinal decompression and broad-spectrum antibiotics, when blood/stool cultures are positive. Theoretically, when the disease develops into Bell's stage III phase, a surgical intervention should be considered, though the supportive therapeutic measures outlined above [1]. Perforation and pneumoperitoneum are known indicators for surgery. However, the situation after surgery becomes more complicated. Theoretically, the best time for the operation is the intestinal wall full-thickness necrosis before the bowel perforation occurred. Therefore, it would be a great benefit to perform surgery by the time of intestinal necrosis before perforation. Fibrinogen is synthesized and secreted by the hepatocytes, particularly at an acute-phase inflammatory bowel disease [4]. The concentration of plasma fibrinogen ranges between $2 \mathrm{~g} / \mathrm{L}$ and $4 \mathrm{~g} / \mathrm{L}$ and the half-life is about 4 days [5]. Fibrinogen is an important component of the coagulation cascades, 
as well as a major determinant factor of blood flow and blood viscosity. It also plays a vital role in a variety of physio pathological processes in the body, including inflammation, atherogenesis and thrombogenesis [6]. The identification of the molecular mechanisms linking inflammation and coagulation has highlighted the coagulation cascade factors as new targets for therapeutic intervention in various inflammatory human diseases. Moreover, the increase of plasma is associated with progression of diseases such as vascular disruption or infection, inflammation and tissue necrosis diseases [7]. Therefore, a retrospective study was used to analyze the relationship between the fibrinogen concentration and intestinal necrosis, which might predict intestinal necrosis in NEC children before perforation for determining the optimal surgical intervention, ultimately reduce postoperative complications and mortality.

\section{Materials and Methods}

Data was acquired from the 2nd Affiliated Hospital \& Yuying children's Hospital of Wenzhou Medical University. All the children were newborns and enrolled between October 2008 and August 2018. Totally 456 children were diagnosed with NEC during this period. 178 of patients were treated with surgery. All the children were included in the study if they received surgical interventions. The plasma fibrinogen level was examined about $2 \mathrm{~h}$ before operation. According to the procedure, the children who had a history of blood transfusion before the fibrinogen test, comorbidity of liver disease, appendiceal perforation or other disease that may influent the level of plasma fibrinogen and whose laboratory test data missing were excluded. Ultimately, 168 children were included in our statistical analysis after screening. First of all, we divided all the children into Intestinal necrosis (IN $n=129$ ) and No intestinal necrosis (NIN n=39) groups. Secondly, we divided the children into Intestinal perforation (IP $\mathrm{n}=83$ ) and No intestinal perforation (NIP $n=85$ ) groups for further research. Then, these 168 NEC children with surgery were further divided into four types: 68 Infant patients with intestinal perforation and necrosis (IPN), 61 Infant patients of intestinal necrosis without perforation (INWP), 15 Infant patients of intestinal perforation without necrosis (IPWN), and 24 infants without necrosis and perforation (WNP). Patients were diagnosed with NEC and decided to have surgical interventions by the attending physician according to the CRP concentration, plain abdominal radiograph and clinical symptoms of Bell's criteria. The doctor and pathologist made the final diagnosis after surgery. All the diagnosis and treatment of the NEC patients were not affected by this study. All children are performed open surgery. They were divided into several groups according to the presence of perforation and necrosis (including intestinal gangrene) (Figure 1).

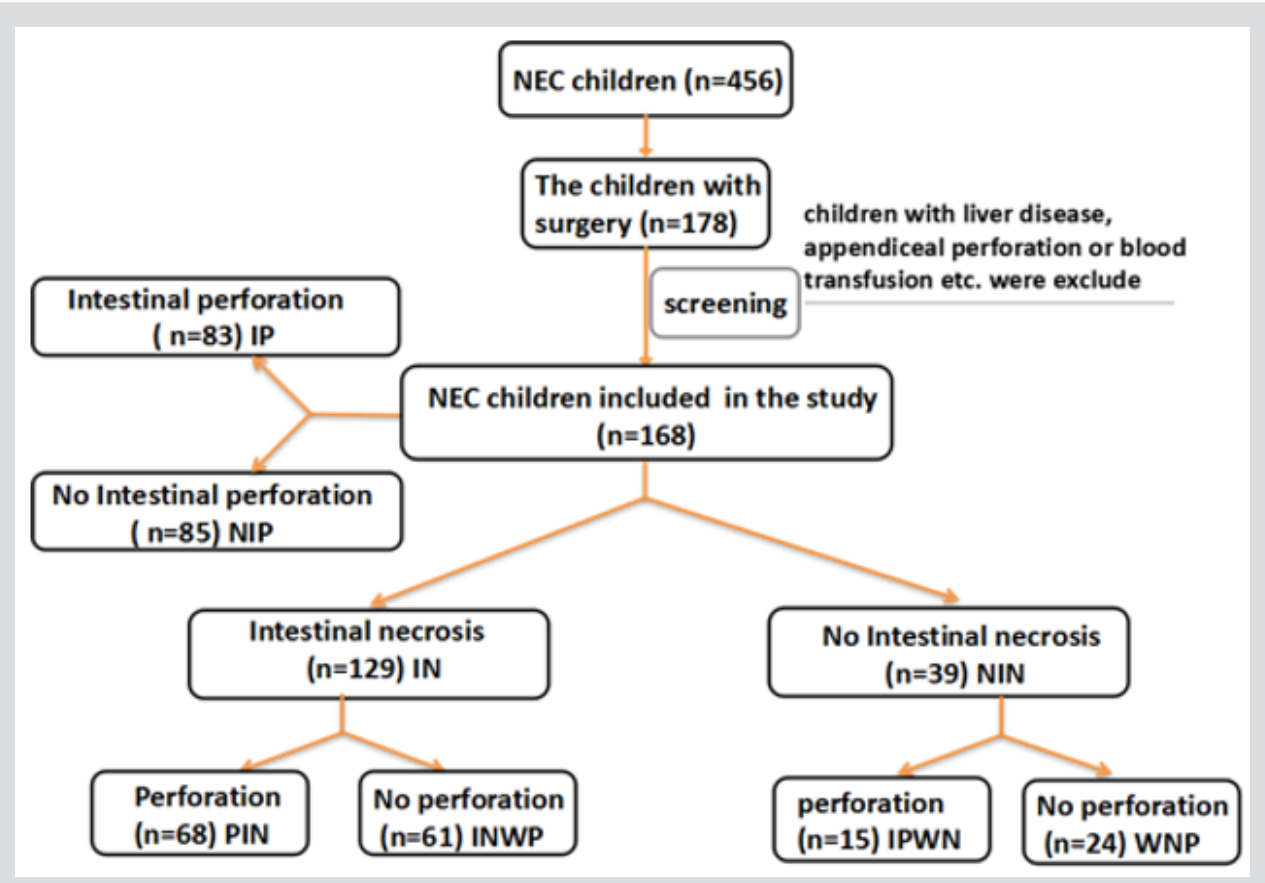

Figure 1: Flow diagram of the study.

\section{Statistical Analysis}

Statistical analysis was performed using SPSS Version 24.0. Analysis of data distribution was assessed by the Shapiro-Wilk test and all samples were normally distributed. Two independent sample t-tests were used to compare the necrosis and no necrosis groups as well as perforation and no perforation groups. Analysis of variance was used to compare necrosis with perforation group, necrosis without perforation group, perforation without necrosis group and without necrosis and perforation group. Mean values and SD were expressed for fibrinogen levels. In addition, calculation of sensitivity, specificity, negative predictive value, and positive predictive value of fibrinogen, as a predictor for the intestinal necrosis of NEC children was included in data analysis. Statistical significance was set at the $5 \%$. 


\section{Results}

There were totally 456 children diagnosed with NEC, 178 (39.03\%) of them underwent surgery treatment. According to the screening conditions (Figure 1), eventually 168 children with surgery were included in our study-110 male (65.48\%), 58 females (34.52\%). 35 children died (20.83\%). Birth weight ranged from $0.63 \mathrm{~kg}$ to $4.50 \mathrm{~kg}$ (median $1.605 \mathrm{~kg}$ ). Gestational age ranged from $24+4$ to $40+4$ weeks (median $30+5 / 7$ weeks). The premature infants accounted for $86.90 \%$ (146). Age of onset ranged from 1 to 90 days (median 2.5 days) (Table 1). First, we divided all the children into IN ( $\mathrm{n}=129)$ and NIN $(\mathrm{n}=39)$ groups, the proportion is $76.79 \%$ and $23.21 \%$, respectively. The IN children had a mean fibrinogen concentration of $3.67 \mathrm{~g} / \mathrm{L}$ (SD $1.25 \mathrm{~g} / \mathrm{L}$, range 1.05-6.68 $\mathrm{g} / \mathrm{L}$, median $3.59 \mathrm{~g} / \mathrm{L}$ ), which was significantly higher than the mean fibrinogen concentration $(2.71 \mathrm{~g} / \mathrm{L}$, SD $1.19 \mathrm{~g} / \mathrm{L}$, range 0.81-5.85 $\mathrm{g} / \mathrm{L}$, median $2.59 \mathrm{~g} / \mathrm{L}$ ), of NIN children ( $\mathrm{P}=0.000$ ) (Figure 2). From the result of our receiver operating characteristic curve analysis for plasma fibrinogen concentration, the fibrinogen concentration is greater than $3.165 \mathrm{~g} / \mathrm{L}$ if NEC children would be more likely to have bowel necrosis, which had an optimal ratio of sensitivity 0.667 and specificity 0.769 (area under receiver operating characteristic curve is 0.721 ) (Figure 3). Secondly, we divided the children into IP ( $n=83$ ) and NIP ( $n=85)$ group, the proportion is $49.40 \%$ and $50.60 \%$, respectively. The mean fibrinogen concentration was $3.57 \mathrm{~g} / \mathrm{L}$ (SD $1.32 \mathrm{~g} / \mathrm{L}$, range 1.05-6.38 g/L, median $3.48 \mathrm{~g} / \mathrm{L}$ ) and $3.32 \mathrm{~g} / \mathrm{L}$ (SD $1.27 \mathrm{~g} / \mathrm{L}$, range 0.81-6.68 g/L, median 3.33g/L), respectively, however, there are no significant differences between IP and NIP children ( $\mathrm{P}=0.216$ ) (Figure 4).

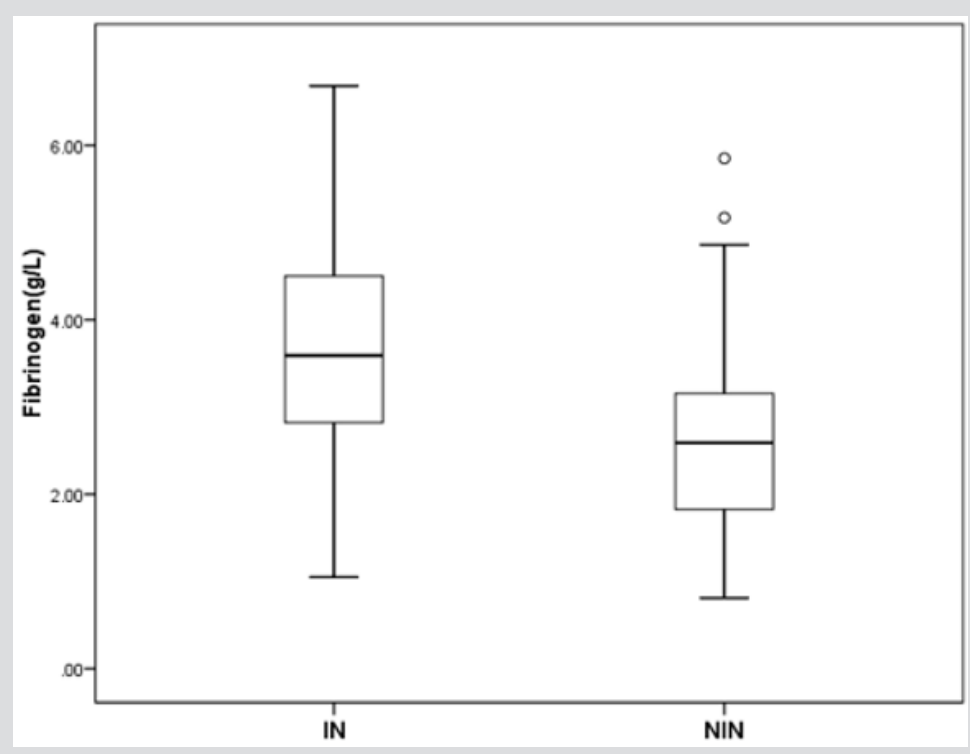

Figure 2: Box-and-whisker plot showing fibrinogen concentration in IN and NIN groups. There was statistical significance between IN group $(\bar{x}=3.67 \mathrm{~g} / \mathrm{L})$ and NIN group $\left(x^{-}=2.71 \mathrm{~g} / \mathrm{L}\right)(\mathrm{P}=0.000)$.

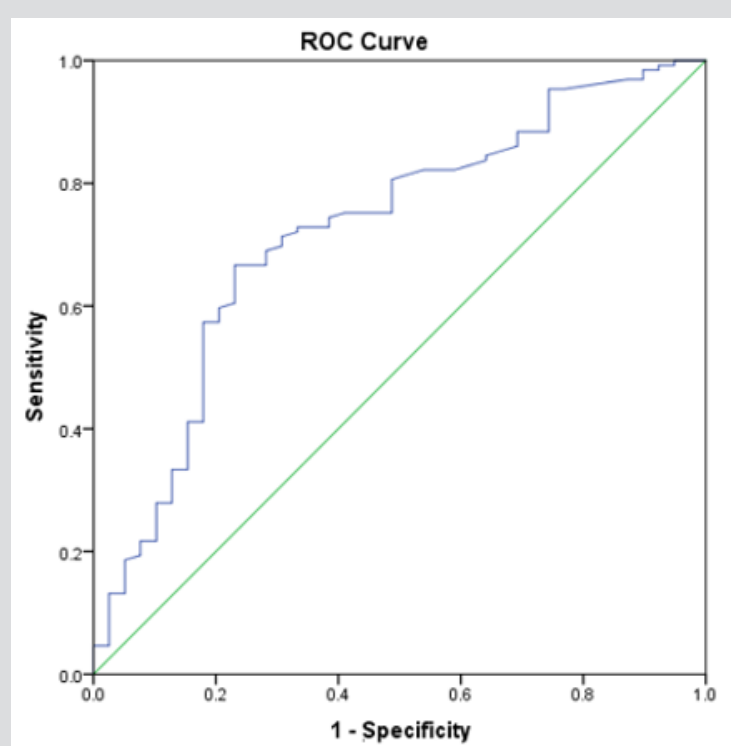

Figure 3: Receiver operating characteristic curve analysis for the fibrinogen concentration showed it had the area under receiver operating characteristic curve (0.72). 


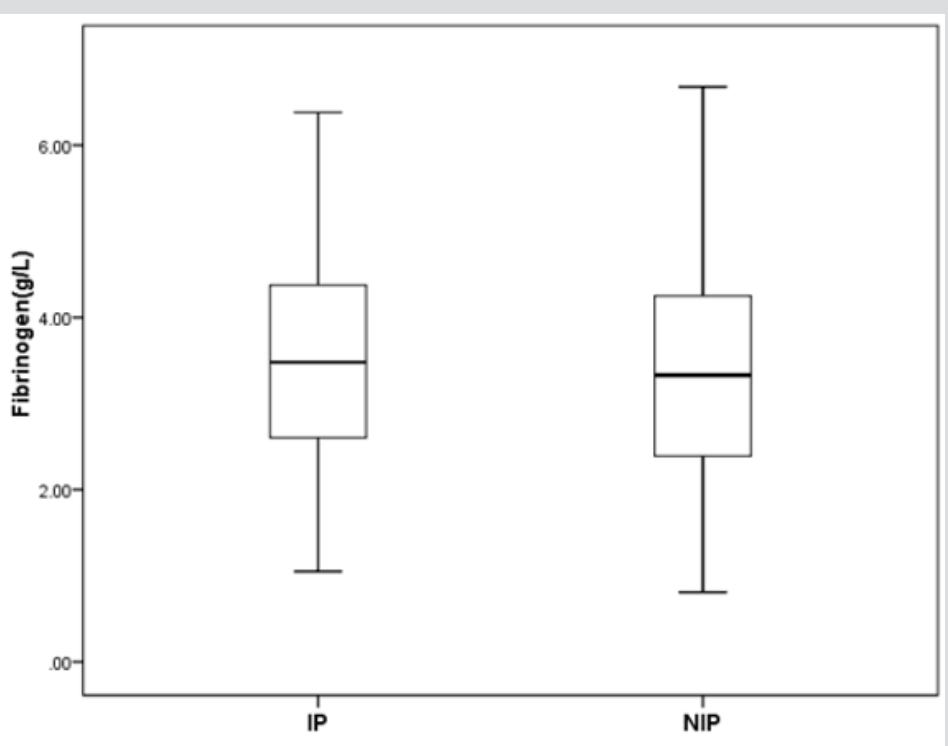

Figure 4: Box-and-whisker plot showing fibrinogen concentration in IP and NIP groups. No statistical significance was detected between IP group $\left(x^{-}=3.57 \mathrm{~g} / \mathrm{L}\right)$ and NIP group $\left(x^{-}=3.32 \mathrm{~g} / \mathrm{L}\right)(\mathrm{P}=0.216)$.

Table 1: Basic statistics of the NEC children with surgery $(n=168)$ in the present study.

\begin{tabular}{|c|c|c|c|c|c|}
\hline & Median & Minimum & Maximum & Mean & SD \\
\hline Birth weight (kg) & 1.605 & 0.630 & 4.500 & 1.787 & 0.728 \\
\hline Gestational age (week) & $30+5 / 7$ & $24+4 / 7$ & $40+4 / 7$ & $31+5 / 7$ & 26.609 \\
\hline Age of onset (day) & 2.5 & 1 & 90 & 10.441 & 17.414 \\
\hline
\end{tabular}

Furthermore, these 168 NEC children with surgery were further divided into four types: IPN group ( $n=68)$, INWP group $(n=61)$, IPWN group $(n=15)$ and WNP $(n=24)$. The means of fibrinogen concentration was $3.66 \mathrm{~g} / \mathrm{L}$ (SD $1.32 \mathrm{~g} / \mathrm{L}$, range 1.05$6.38 \mathrm{~g} / \mathrm{L}$, median $3.52 \mathrm{~g} / \mathrm{L}$ ), $3.68 \mathrm{~g} / \mathrm{L}$ (SD 1.18g/L, range 1.39-6.68 g/L, median 3.62g/L), $3.18 \mathrm{~g} / \mathrm{L}$ (SD $1.29 \mathrm{~g} / \mathrm{L}$, range 1.21-5.85 g/L, median $2.90 \mathrm{~g} / \mathrm{L}$ ), $2.41 \mathrm{~g} / \mathrm{L}$ (SD $1.04 \mathrm{~g} / \mathrm{L}$, range $0.81-5.17 \mathrm{~g} / \mathrm{L}$, median $2.40 \mathrm{~g} / \mathrm{L}$ ), respectively. According to the statistical analysis, there were significant differences between INP group and WNP group ( $\mathrm{P}=0.000)$, INWP and WNP group $(\mathrm{P}=0.000)$, as well as IPWN group and WNP group $(\mathrm{P}=0.048)$. In addition, there were no significant differences between INP group and INWP group $(\mathrm{P}=0.916)$, INP and IPWN groups $(\mathrm{P}=0.209)$, INWP and IPWN group ( $\mathrm{P}=0.155)$, respectively (Figure 5 ). Therefore, we can make a conclusion through the statistical analysis that there is a significant difference between the fibrinogen concentration of IN and NIN groups.

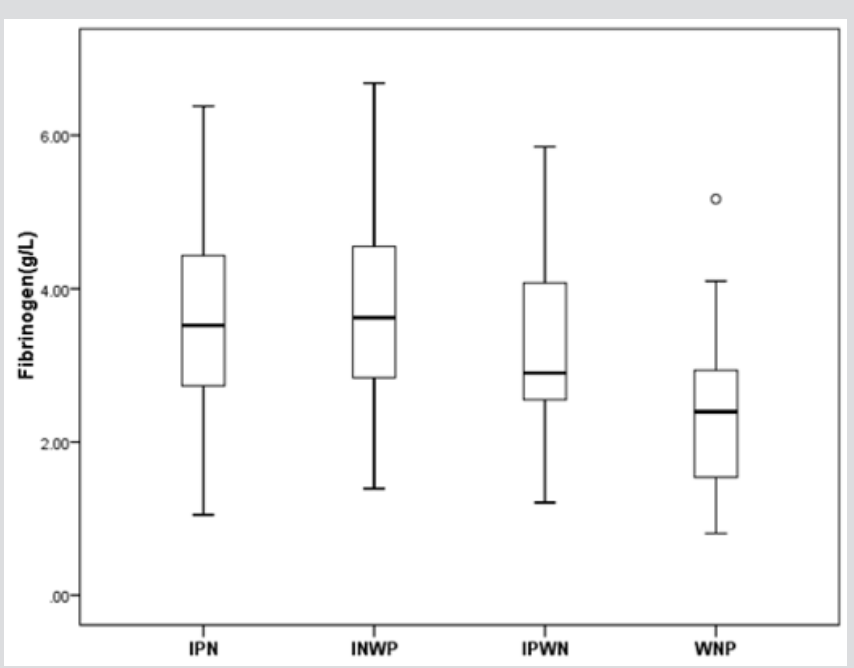

Figure 5: Box-and-whisker plot showing fibrinogen concentration in IPN、INWP、IPWN and WNP groups. There were statistically significant differences between IPN $\left(x^{-}=3.66 \mathrm{~g} / \mathrm{L}\right)$ and WNP groups $(\bar{x}=2.41 \mathrm{~g} / \mathrm{L})(\mathrm{P}=0.000), \mathrm{INWP}(3.68 \mathrm{~g} / \mathrm{L})$ and WNP groups $(\bar{x}=2.41 \mathrm{~g} / \mathrm{L})(\mathrm{P}=0.000)$, IPWN $(x=3.18 \mathrm{~g} / \mathrm{L})$ and WNP groups $(\bar{x}=2.41 \mathrm{~g} / \mathrm{L})(\mathrm{P}=0.048)$. No significant difference was found between IPN and INWP groups $(P=0.916), I P N$ and IPWN groups $(P=0.209)$, INWP and IPWN groups $(P=0.155)$. 


\section{Discussion}

As more and more VLBW preterm infants survive, the proportion at the risk of NEC increases. According to SPSS analysis, approximately $20-40 \%$ of NEC children require surgery. Although the mortality rate of NEC has decreased to $20 \%$ due to earlier diagnosis and the improvement of intensive care, the mortality rate is higher $(50 \%)$ for patients who required operation $[1,8]$. In the clinical diagnosis, Bell's stage of NEC was used as a reference [9]. Srinivasjois's research reported that CRP became abnormal in both stage II and stage III NEC and can distinguish from the benign form of NEC suspect, pneumatosis intestinalis, or spuriously suggestive GI conditions [10]. In most cases, only when Bell's stage III symptoms appear, surgical intervention may be considered. Some radiological signs (portal venous gas, persistent fixed loop, comprehensive intestinal expansion progressing to asymmetrical intestinal expansion, or ascites) and laboratory features (severe thrombocytopenia, neutropenia, or acidosis) might provide a general judgment; however, the only pneumoperitoneum is the known indication for surgery. And this may cause complications and miss the optimal surgical timing. In this retrospective study, there were 168 NEC children of intestinal necrosis in which up to 85 cases with intestinal perforation. There were many postoperative complications of NEC children with intestinal perforation and large proportion intestinal necrosis. To confirm this status in clinical is complicated. Therefore, we should make efforts to improve diagnosis and surgical timing. Through the study, we found that the fibrinogen concentration is greater than $3.165 \mathrm{~g} / \mathrm{L}$ in the patient with intestinal necrosis, regardless of the bowel perforated or not. This might help us discover the NEC children with bowel necrosis before the perforation appearance and suggest that we should perform surgery timely.

Fibrinogen is a glycoprotein protein, made up of three distinct polypeptide chains $\mathrm{A} \alpha, \mathrm{B} \beta$, and $\gamma[5,11]$. It plays an important role in pathological conditions, including post-injury, infection, inflammation and disease associated with vascular disruption. In these conditions, plasma fibrinogen concentration usually increases by several folds [12]. It is generally acknowledged that NEC is severe intestine inflammatory disorder, which often occurs, in premature infants. Premature birth, oxygen deficit, immaturity of intestinal barrier, immune defense, excessive feeding, bacterial infection and cyanotic congenital heart disease are predisposing risk factors of $\mathrm{NEC}$, and these factors can induce inflammation reaction. In vitro and in vivo studies indicated that fibrinogen modulates inflammation by regulating leukocyte migration, and directly altering the leukocytes and endothelial cells inflammatory response through an increased cytokine/chemokine response [13]. Fibrinogen plays an important biological role not only in the inflammatory response related infection and disease but also in hemostasis, reproduction and tissue repair. Coagulation and inflammation are activated by the same types of challenges and correlate both temporally and spatially in the same tissues [7]. Fibrinogen is an essential protein of the blood coagulation system and it becomes fibrin when triggered by the procoagulant stimulus. NEC is a severe intestine inflammatory disease. The microcirculation is highly responsive and participant in inflammatory response. All segments of the microvasculature (arterioles, capillaries, and venules) show characteristic phenotypic changes during inflammation, which appear to be directed to enhancing the delivery of inflammatory cells to the infected or injured tissues, isolating the region from healthy tissue and the systemic circulation and setting the stage for tissue repair and regeneration. The most characterized responses of the microcirculation to inflammation include impaired vasomotor function, reduced capillary perfusion, adhesion of leukocytes and platelets, activation of the coagulation cascade, and enhanced thrombosis, increased vascular permeability and an increase in the rate of proliferation of blood and lymphatic vessels [14]. Moreover, hyperfibrinogenemia directly promotes thrombosis and thrombolysis resistance via enhanced fibrin formation and stability [15]. All these factors will lead to the high possibility of intestinal necrosis in NEC children with hyperfibrinogenemia.

\section{Conclusion}

From our experience and the review, we found that hyperfibrinogenemia can help us identify the NEC children with intestinal necrosis before surgery. It may provide reference for the timing of optimal surgical intervention, ultimately reduce postoperative complications and mortality in NEC children.

\section{References}

1. Lin PW, Stoll BJ (2006) Necrotising enterocolitis. Lancet 368(9543): 1271-1283.

2. Kamitsuka MD, Horton MK, Williams MA (2000) The incidence of necrotizing enterocolitis after introducing standardized feeding schedules for infants between 1250 and 2500 grams and less than 35 weeks of gestation. Pediatrics 105(2): 379-384.

3. Tepas JJ, Leaphart CL, Plumley D, Sharma R, Celso BG, et al. (2010) Trajectory of metabolic derangement in infants with necrotizing enterocolitis should drive timing and technique of surgical intervention. Journal of the American College of Surgeons 210(5): 847-852, 852-844.

4. Callea F, Giovannoni I, Sari S, Guldal E, Dalgic B, et al. (2017) Fibrinogen Gamma Chain Mutations Provoke Fibrinogen and Apolipoprotein B Plasma Deficiency and Liver Storage. International journal of molecular sciences 18 (12).

5. Tennent GA, Brennan SO, Stangou AJ, O Grady J, Hawkins PN, et al. (2007) Human plasma fibrinogen is synthesized in the liver. Blood 109(5): 1971-1974.

6. Arshinov AB, Maslova IG (2010) [Role of the infection and inflammation in atherosclerosis development (literature review)]. Angiology and vascular surgery 17(1): 35-41

7. Davalos D, Akassoglou K (2012) Fibrinogen as a key regulator of inflammation in disease. Seminars in immunopathology 34 (1):43-62.

8. Khalak R, D Angio C, Mathew B, Wang H, Guilford S, et al. (2018) Physical examination score predicts need for surgery in neonates with necrotizing enterocolitis. Journal of perinatology: official journal of the California Perinatal Association 38(12): 1644-1650.

9. Pourcyrous M, Korones SB, Yang W, Boulden TF, Bada HS (2005) C-reactive protein in the diagnosis, management, and prognosis of neonatal necrotizing enterocolitis. Pediatrics 116(5): 1064-1069. 
10. Srinivasjois R, Nathan E, Doherty D, Patole S (2010) Prediction of progression of definite necrotising enterocolitis to need for surgery or death in preterm neonates. The journal of maternal-fetal \& neonatal medicine: the official journal of the European Association of Perinatal Medicine, the Federation of Asia and Oceania Perinatal Societies, the International Society of Perinatal Obstet 23(7): 695-700.

11. Weisel JW (2005) Fibrinogen and fibrin. Advances in protein chemistry 70: 247-299.

12. Adams RA, Passino M, Sachs BD, Nuriel T, Akassoglou K (2004) Fibrin mechanisms and functions in nervous system pathology. Molecular interventions 4(3): 163-176.

ISSN: 2574-1241

DOI: 10.26717/BJSTR.2019.16.002866

Xiaoming Chen. Biomed J Sci \& Tech Res

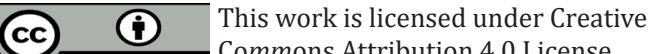

Submission Link: https://biomedres.us/submit-manuscript.php
13. Qi J, Goralnick S, Kreutzer DL (1997) Fibrin regulation of interleukin-8 gene expression in human vascular endothelial cells. Blood 90(9): 35953602

14. Granger DN, Senchenkova E (2010) Inflammation and the Microcirculation Integrated Systems Physiology-From Cell to Function. San Rafael (CA)

15. Machlus KR, Cardenas JC, Church FC, Wolberg AS (2011) Causal relationship between hyperfibrinogenemia, thrombosis, and resistance to thrombolysis in mice. Blood 117(18): 4953-4963.

$\begin{array}{ll}\text { BIOMEDICAL } & \text { Assets of Publishing with us } \\ \text { RESEARCHES } & \text { - Global archiving of articles } \\ & \text { - Immediate, unrestricted online access } \\ & \text { - Rigorous Peer Review Process } \\ & \text { - Authors Retain Copyrights }\end{array}$

